\title{
Orbital neurilemmoma
}

\section{Presenting as retrobulbar neuritis}

\author{
HARI MOHAN AND D. K. SEN \\ Department of Ophthalmology, Irwin Hospital, New Delhi, India
}

Neurilemmoma of the orbit is a localized, encapsulated, benign nerve sheath tumour which grows very slowly and possibly intermittently, and has no distinctive clinical features. (Reese, 1963). When large enough it causes exophthalmos and sometimes blurring of vision through pressure on the optic nerve (Reese, I963; Sharma and Kulshrestha, I96I) The motility of the eyeball may also be impaired. This tumour has rarely been recorded 8 in the literature and we have been unable to find any previous report that it may first? present with the clinical features of retrobulbar neuritis.

\section{Case report}

A Hindu schoolgirl aged 14 years came to the eye out-patient department complaining of defective $\vec{\theta}$ vision in the right eye for Io days. The onset had been fairly sudden and was at first painless.

\section{Examination}

The left eye and its adnexa were normal, with visual acuity $6 / 6$.

In the right eye the visual acuity was 6/24. There was mild local pain on moving the eye but noo limitation of movement. The pain was increased by pressure on the globe. The pupil reacted to® light but the contraction was not maintained under bright illumination. The fundus was examined $\overrightarrow{\vec{O}}$ by direct and indirect ophthalmoscopy and appeared to be normal.

Investigation of the visual fields showed a central scotoma which was relative for colours. Skiagrams of the paranasal sinuses and orbits gave no diagnostic information.

The case was thought to be one of retrobulbar neuritis, but a thorough systemic and neurologicalo․ examination did not reveal any specific cause of the neuritis.

\section{Therapy}

The patient was given non-specific treatment with heavy doses of vitamin $B_{1}$ and $B_{12}$ intramuscularly and glucocorticoids orally.

\section{Progress}

As there was no recovery of vision even at the end of 3 weeks she stopped attending the hospital, but after 3 years she returned complaining of loss of sight in the right eye with exophthalmos which hados been gradually increasing for the past $2 \frac{1}{2}$ years. She stated that her sight had been steadily diminish- $N$ ing since she had first attended the hospital.

\section{Examination}

There was no perception of light in the affected eye. The globe was displaced forwards, upwards, and outwards. Movements were restricted in all directions, especially downwards. The con $\stackrel{?}{+}$ junctiva, cornea, and iris were normal. The pupil was dilated and fixed. The optic disc showed pressure type atrophy. Palpation of the orbital margins showed no abnormality, and no orbita mass could be felt even on deep palpation. Skiagrams of the skull, orbits, optic foramina, and? paranasal sinuses, and also blood studies were negative. 


\section{Operation}

Kronlein's lateral orbitotomy was performed under general anaesthesia and exploration of the orbit revealed a well-encapsulated firm elastic mass located in the lower medial quadrant. Though there was some difficulty because of the situation of the tumour the whole mass could be shelled out with the index finger.

Result

The post-operative period was uneventful, and histopathological examination identified the tumour as neurilemmoma with Antoni cells type-A and type-B (Figure).

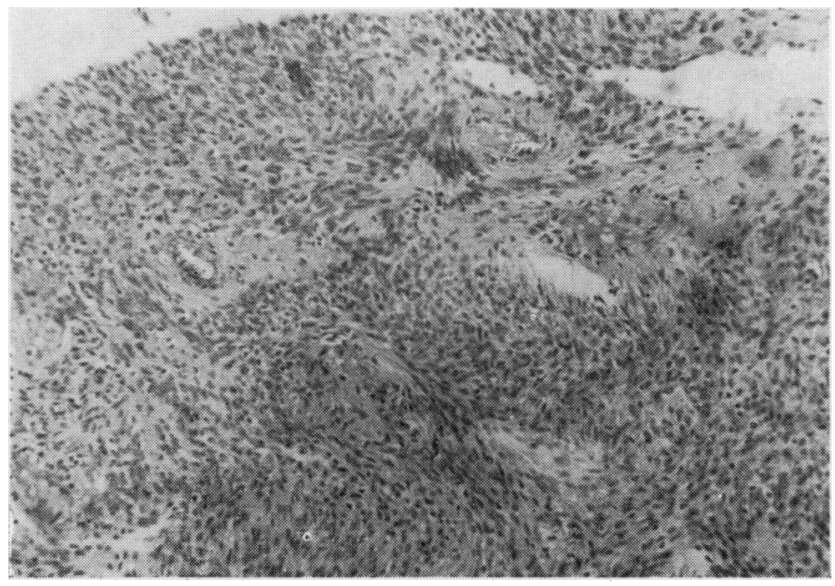

FIGURE Photomicrograph of tumour tissue, showing fascicular arrangement of cells. Haematoxylin and eosin. $\times 100$

\section{Comment}

It is to be noted that neurilemmomata and other orbital neoplasms may sometimes present as cases of retrobulbar neuritis with no evidence of the presence of a tumour, yet to miss the true diagnosis at this early stage could be disastrous. It is, therefore, imperative to exclude the presence of orbital neoplasm in all cases of retrobulbar neuritis of obscure aetiology. Docter and Kennedy (1948) stated that such tumours were always palpable through the lid and Sharma and Kulshrestha (Ig6I) also palpated a mass through the lid in their cases, but this did not prove to be possible in the present case. Some of the reported cases showed signs indicative of von Recklinghausen's disease, such as pigmented spots over the body, cutaneous nodules, and a dehiscence in the roof of the orbit, but none was present in this case.

\section{Summary}

A case of neurilemmoma of the orbit presented as retrobulbar neuritis.

\section{References}

DOGTER, L., and KENNEDY, R. J. (1948) Cleveland Clin. Quart., 15, 99 DUKE-ELDER, S. (1952) “Textbook of Ophthalmology", vol. 5, p. 558o. Kimpton, London REESE, A. B. (1963) "Tumors of the Eye", 2nd ed., p. 201. Hoeber, New York Sharma, B. C., and kulshrestha, O. P. (1961) Amer. 7. Ophthal., 51, 522 